\title{
PREVALÊNCIA DA VIOLÊNCIA DOMÉSTICA CONTRA MULHERES ATENDIDAS NO PLANEJAMENTO FAMILIAR EM MATERNIDADE PÚBLICA
}

\section{PREVALENCE OF HOUSEHOLD VIOLENCE AGAINST WOMEN SERVED IN FAMILY PLANNING IN PUBLIC MATERNITY}

\author{
Adrielly Santos Jacinto Patricio ${ }^{1}$ \\ Emanuella de Castro Marcolino ${ }^{2}$ \\ Lindemberg Arruda Barbosa ${ }^{3}$ \\ Fihama Pires Nascimento ${ }^{4}$ \\ Renata Clemente dos Santos ${ }^{5}$
}

RESUMO: OBJETIVO: avaliar a prevalência da violência doméstica contra mulheres atendidas no planejamento familiar em maternidade pública e como específicos: caracterizar a violência doméstica sofrida pelas participantes do estudo e determinar os comportamentos de riscos relacionados à violência doméstica contra mulheres atendidas no planejamento familiar de uma maternidade pública. MÉTODO: pesquisa transversal de caráter exploratório com abordagem quantitativa. A amostra foi composta por 66 mulheres. Os dados foram coletados por meio de um instrumento adaptado específico de violência e analisados no SPSS por meio de estatística descritiva. Os achados foram coletados após parecer favorável do comitê de ética e pesquisa sob parecer número 2.679.482. RESULTADOS: os dados expressaram que a maioria das mulheres estava na faixa etária de 23 a 37 anos, se autodeclaram pardas ou brancas e tinham companheiro fixo. A prevalência de violência doméstica entre as mulheres foi de $43,1 \%$, das que sofreram alguma situação de violência, o braço foi a área traumatizada mais indicada $(4 ; 6,2 \%)$; a maioria relatou não ter realizado sexo contra sua vontade nos últimos 12 meses $(55 ; 84,6 \%)$. O principal perpetrador da violência foi o marido $(11 ; 16,9 \%)$, entretanto

\footnotetext{
1 Graduada em Enfermagem pela UNIFACISA Centro Universitário; E-mail: adriellysantos1989@gmail.com.

${ }^{2}$ Docente do curso de Enfermagem da UNIFACISA Centro Universitário. Doutora em Enfermagem pela UFRN; E-mail: emanuella.de.castro@gmail.com.

3 Discente do curso de Enfermagem na UNIFACISA Centro Universitário; E-mail: lindemberg.uf@gmail.com.

4 Discente do curso de Enfermagem na UNIFACISA Centro Universitário; E-mail: fihamapires0@gmail.com.

5 Docente do curso de Enfermagem da UNIFACISA Centro Universitário. Doutoranda em Enfermagem pela UFPB; E-mail: renata.clemente@hotmail.com.
} 
a maior parte das mulheres afirmou não ter medo destes $(58 ; 89,2 \%)$. Quanto a violência sexual a maioria foi cometida pelo marido $(3 ; 4,6 \%)$. CONCLUSÕES: apesar da violência doméstica auto relatada entre mulheres atendidas no planejamento familiar não predominar entre as participantes, destaca-se a necessidade de maiores investigações do fenômeno em busca de respostas para tais achados haja vista o alto número de recusa as respostas do questionário.

Palavras chave: Violência doméstica. Violência contra a mulher. Planejamento Familiar.

ABSTRACT: OBJECTIVE: To evaluate the prevalence of domestic violence against women treated in family planning at a public maternity hospital and as specific objectives: to characterize the domestic violence suffered by study participants and to determine the risk behaviors related to domestic violence against women treated in family planning at a public maternity hospital. METHOD: exploratory crosssectional research with quantitative approach. The sample consisted of 66 women. Data were collected using a specific adapted instrument of violence and analyzed in the SPSS using descriptive statistics. The findings were collected after the ethics and research committee endorsement under document number 2.679.482. RESULTS: The data results expressed that most women were between 23 and 37 years old, self-described brown or white and had a steady partner. The prevalence of domestic violence among women was 43.1\%; of those who suffered any violence, the arm was the most indicated traumatized area (4; 6.2\%); most reported not having unconsent sex in the last 12 months (55; 84.6\%). The main perpetrator of violence was their husband $(11 ; 16.9 \%)$, however most women said they were not afraid of their husbands (58; 89.2\%). Regarding sexual violence, the majority was committed by the husband (3; 4.6\%). CONCLUSIONS: Although self-reported domestic violence among women assisted in family planning did not predominate among participants, there is a need for further investigation of the phenomenon in search of answers to these findings, given the high number of refusal to answer the questionnaire.

Keywords: Domestic violence. Violence against women. Family planning. 


\section{INTRODUÇÃO}

A violência contra a mulher tem sido abordada como um problema universal de saúde pública, em grande número de vezes de forma silenciosa e dissimulada, tanto pelo impacto negativo que provoca na qualidade de vida das vítimas quanto pelas implicações nos diferentes cenários, incluindo o jurídico, o econômico, o social e o de saúde. Apesar disso, embora se reconheça sua dimensão multidisciplinar, estudiosos destacam a invisibilidade social desse fenômeno, muitas vezes atribuída ao silêncio de vítimas e aos impasses comunicacionais entre vítima e profissionais (FERREIRA et al., 2015).

Portanto, a violência contra a mulher consiste em qualquer ato violento baseado no gênero, que resulte, ou tenha probabilidade de resultar, em dano físico, sexual, psicológico ou sofrimento para a mulher, incluindo a ameaça de praticar tais atos, a coerção ou privação arbitrária da liberdade em ambiente público ou privado (SILVA; OLIVEIRA, 2015).

A violência doméstica contra a mulher caracteriza-se pelas situações de violência que ocorrem no âmbito domiciliar produzidas por membros da própria família ou não, inclui-se empregados (as), pessoas que convivem esporadicamente, agregados (MIURA et al., 2018).

Segundo Ribeiro e Coutinho (2011), um em cada cinco dias de falta ao trabalho é consequência da violência sofrida pelas mulheres dentro de suas casas; a cada cinco anos a mulher perde o equivalente a um ano de vida saudável por conta da violência doméstica; na América Latina, o índice é de aproximadamente $25 \%$ a $50 \%$ das mulheres atingidas; por consequência, uma mulher que sofre violência doméstica, tem o rendimento laboral comprometido e ganha menos que aquelas que não sofrem.

Calcula-se que o custo da violência contra a mulher é de aproximadamente entre $1,6 \%$ e $2 \%$ do PIB de um país, estes dados configuram que a violência 
doméstica sai do seu âmbito para atingir outros setores da sociedade como um todo (FONSECA; RIBEIRO; LEAL, 2012).

O sentimento de impotência, vergonha, culpa, decepção, sofrimento, tornamse constantes para a mulher que sofre violência doméstica. Esta se torna passiva e submissa, frustrada por não se fazer ouvir e respeitar. Algumas idealizam um relacionamento de sonhos, onde esperam que o companheiro mude em um "passe de mágica”, o que faz com que as decepções se tornem constantes, e se intensifique os dados psíquicos e emocionais (FONSECA; RIBEIRO; LEAL, 2012).

O fenômeno em discussão produz repercussões em vários aspectos da vida da mulher, no trabalho, nas relações sociais e na saúde, assim atingindo a sociedade como um todo. Apesar da violência doméstica ser tão frequente em nossa sociedade, ainda não possui a devida atenção necessária, pois é tratado como um problema íntimo a ser resolvido no seio familiar, o que torna a mulher refém do contexto onde está inserida (FONSECA; RIBEIRO; LEAL, 2012).

Acredita-se, portanto, que a temática é de grande relevância haja vista seus impactos na vida da mulher, serviços de saúde e a sociedade, assim, questionamos: Qual a prevalência de violência doméstica contra mulheres atendidas no setor de planejamento familiar da maternidade Instituto de Saúde Elpídio de Almeida (ISEA) em Campina Grande-PB?

Dessa forma, o presente estudo tem como objetivo geral avaliar a prevalência da violência doméstica contra mulheres atendidas no planejamento familiar em maternidade pública e como específicos caracterizar a violência doméstica sofrida pelas participantes do estudo e determinar os comportamentos de riscos relacionados à violência doméstica contra mulheres atendidas no planejamento familiar do ISEA. 


\section{MÉTODO}

Trata-se de uma pesquisa transversal de caráter exploratório com abordagem quantitativa, desenvolvida na Unidade de Saúde Instituto Saúde Elpídio de Almeida (ISEA), localizada no do município de Campina Grande/PB.

$O$ atendimento na maternidade ISEA, em Campina Grande, compõe o sistema municipal de saúde, sendo referência nas especialidades de ginecologia e obstetrícia, neonatologia, fisioterapia, serviço social, psicologia, ambulatório de pediatria, odontologia, radiologia e banco de leite, oferecendo serviços de saúde para o município supracitada e a região circunvizinha.

A população do estudo foi composta por mulheres atendidas no setor do planejamento familiar no referido serviço de saúde, com estimativa média de 85 atendimentos. A amostra definida a partir dessa população de mulheres atendidas por meio do cálculo de amostra finita, totalizando uma amostra de 65 mulheres. Foram inclusas mulheres atendidas no setor do planejamento familiar com idade acima de 18 anos e excluídas aquelas que estavam gestantes e que não apresentavam condições psíquicas ou dificuldade de compreensão devido a algum déficit intelectual ou sensorial.

Para a coleta dos dados foi utilizado um questionário (SILVA, 2006) inspirado em uma adaptação do instrumento Abuse Assessment Screen (ASS) e ocorreu entre os meses de fevereiro e março de 2018. As colaboradoras foram abordadas na sala de espera do planejamento familiar à medida que aguardavam pelo atendimento. Para a participação na pesquisa foi necessária a assinatura prévia do Termo de Consentimento Livre e Esclarecido (TCLE), seguida da aplicação do instrumento em ambiente reservado que possibilitasse a aplicação do instrumento de maneira a garantir o sigilo e a preservação do sujeito.

Para análise dos dados utilizou-se o programa estatístico Statistical Package for the Social Sciences - SPSS por meio de estatística descritiva definiu-se frequências absolutas e relativas. 
O estudo foi submetido à análise do Comitê de Ética em Pesquisa do CESED/FCM e a comissão de Apreciação de Pesquisa na Unidade de Saúde do ISEA, assim iniciou-se o estudo a partir do parecer favorável de número 2.679.482.

\section{RESULTADOS}

Quanto às características individuais, a maioria das mulheres estava na faixa etária de 23 a 37 anos correspondendo a $72,2 \%$, se autodeclaram pardas ou brancas $(53 ; 81,6 \%)$, tinham companheiro fixo $(53 ; 81,6 \%)$, afirmaram ter ensino fundamental $(26 ; 40,0 \%)$, exerciam trabalho informal $(19 ; 29,3 \%)$, tinham filhos (62; $95,4 \%)$, com renda familiar de $\mathrm{R} \$ 76,00$ a 300,00 (20; 30,8\%). Quanto à caracterização do companheiro a maioria estava na faixa etária de 29 a 37 anos (23; $32,4 \%,), 55,4 \%$ dos companheiros estudaram e declararam que a maior parte são pardos $(21 ; 32,3 \%)$ e trabalham informalmente $(30 ; 46,2 \%)$.

A tabela 1 representa a caracterização e prevalência da violência sofrida ou presenciada pelas as mulheres, a maioria referiu não ter presenciado alguma situação de violência em casa $(40 ; 61,5 \%)$, os xingamentos foi a modalidade mais comumente observada $(11 ; 16,9 \%)$; a maioria afirmou não ter sofrido agressão física ou emocional $(37 ; 56,9 \%)$, e negou alguma forma de agressão $(37 ; 56,9 \%)$, o braço foi a área traumatizada mais indicada (4;6,2\%); A maioria das participantes relatou não ter realizado sexo contra sua vontade nos últimos 12 meses $(55 ; 84,6 \%)$. 
Tabela 1. Distribuição de violência sofrida ou presenciada por mulheres atendidas no Planejamento Familiar da Instituto Elpídio de Almeida do Município de Campina Grande, Paraíba, Brasil 2018.

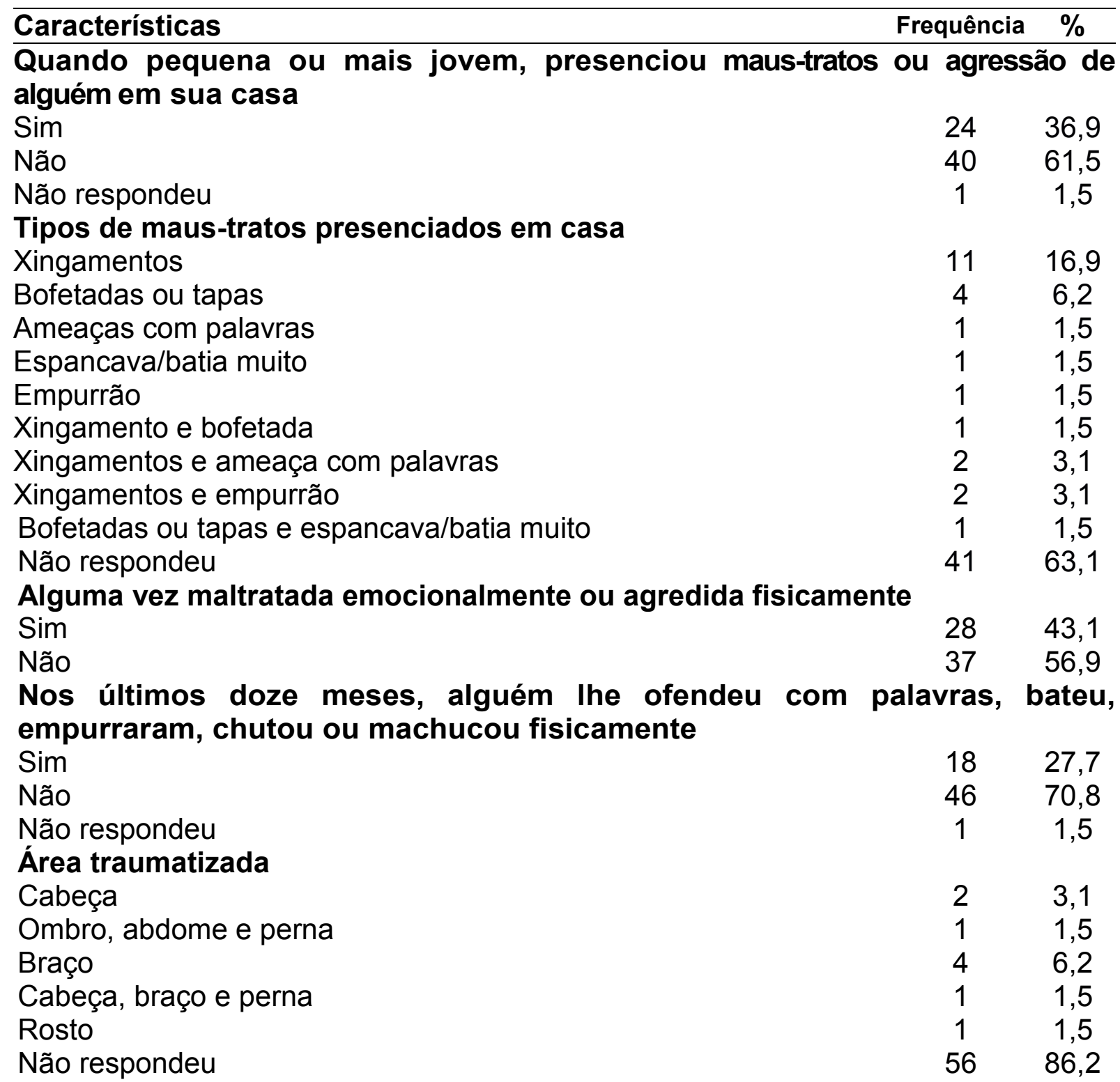

Opção com o maior número, o tipo de mau trato que aconteceu com mais frequência com a senhora

Tapa, empurrão; sem machucar ou ferimento ou dor duradoura $\quad 10 \quad 15,4$

Soco, chute, machucado/"mancha roxa", cortes e/ou dor contínua $\quad 2 \quad 3,1$

Não aconteceu nenhum mau trato dentre os relatados acima $\quad 53 \quad 81,5$

Neste último ano, fez sexo contra a sua vontade

\begin{tabular}{lll} 
Sim & 8 & 12,3 \\
Não & 55 & 84,6 \\
Não respondeu & 2 & 3,1 \\
\hline Total & $\mathbf{6 5}$ & $\mathbf{1 0 0 \%}$
\end{tabular}

Fonte: Dados da pesquisa, 2018. 
A tabela 2 a seguir apresenta dados referentes a distribuição de caracterização do agressor da violência sofrida ou presenciada pelas colaboradoras do estudo, em que é possível perceber que a maioria relatou que quando mais jovem a violência presenciada mais comum foi perpetrada pelo pai $(12 ; 18,5 \%)$, dentre os últimos 12 meses o marido foi o principal perpetrador da violência $(11 ; 16,9 \%)$, entretanto a maioria afirmou não ter medo destes $(58 ; 89,2 \%)$, concernente a violência sexual a maioria foi cometida pelo marido $(3 ; 4,6 \%)$.

Tabela 2. Distribuição do agressor de violência sofrida ou presenciada por mulheres atendidas no Planejamento Familiar da Instituto Elpídio de Almeida do Município de Campina Grande, Paraíba, Brasil 2018.

\begin{tabular}{ccc}
\hline Características & Frequência & $\%$ \\
\hline Principais causadores dos maus-tratos quando pequena e mais jovem \\
Pai & 12 & 18,5 \\
Mãe & 2 & 3,1 \\
Irmão/Irmã & 5 & 7,7 \\
Avós ou tios & 3 & 4,6 \\
Outra pessoa & 3 & 4,6 \\
Não respondeu & 40 & 61,5 \\
Quem provocou a violência nos últimos & 12 meses \\
Marido & 11 & 16,9 \\
Ex-marido & 6 & 9,2 \\
Namorado & 1 & 1,5 \\
Estranho & 1 & 1,5 \\
Outro & 2 & 3,1 \\
Não respondeu & 44 & 67,7 \\
& Medo de alguém citado acima & 10,8 \\
Sim & 7 & 89,2 \\
Não & 58 & 4,6 \\
Marido & Agressor de violência sexual & 3,1 \\
Ex-marido & 3 & 1,5 \\
Estranho & 2 & 90,8 \\
Não respondeu & 1 & $100 \%$ \\
Total & 59 &
\end{tabular}

Fonte: Dados da pesquisa, 2018.

A tabela 3 representa o comportamento de risco apresentados pelas mulheres atendidas, companheiro e familiares no Planejamento Familiar do ISEA quanto a 
caracterização do uso do fumo, de bebidas alcoólicas e outras drogas. Concernente ao fumo às mulheres, em sua maioria, declararam ser não fumantes $(56 ; 86,2 \%)$ e também seus respectivos companheiros $(32 ; 49,2 \%)$, no que diz respeito ao uso de bebida alcoólica a maioria das mulheres responderam que não utilizam $(51 ; 78,5 \%)$, enquanto que o companheiro predominou resposta afirmativa (32;49,2\%). A utilização de drogas foi mais comum pela própria mulher dentre os familiares da residência $(8 ; 12,3 \%)$.

Tabela 3. Distribuição do comportamento de risco de mulheres atendidas, companheiros e familiares no Planejamento Familiar da Instituto Elpídio de Almeida do Município de Campina Grande, Paraíba, Brasil 2018.

\begin{tabular}{|c|c|c|}
\hline \multirow{2}{*}{$\begin{array}{l}\text { Características } \\
\text { Mulher fumante }\end{array}$} & \multicolumn{2}{|c|}{ Frequência \% } \\
\hline & & \\
\hline Sim & 9 & 13,8 \\
\hline Não & 56 & 86,2 \\
\hline \multicolumn{3}{|l|}{ Namorado/marido/companheiro fumante } \\
\hline Sim & 22 & 33,8 \\
\hline Não & 32 & 49,2 \\
\hline Não respondeu & 11 & 16,9 \\
\hline \multicolumn{3}{|l|}{ Uso de bebida alcoólica pela mulher } \\
\hline Só nas festas/socialmente & 6 & 9,2 \\
\hline Uma vez por semana & 6 & 9,2 \\
\hline Duas vezes por semana & 1 & 1,5 \\
\hline Não bebe & 51 & 78,5 \\
\hline Não respondeu & 1 & 1,5 \\
\hline \multicolumn{3}{|c|}{ Uso de bebida alcoólica pelo namorado/marido/companheiro } \\
\hline Sim & 32 & 49,2 \\
\hline Não & 20 & 30,8 \\
\hline Não respondeu & 13 & 20,0 \\
\hline \multicolumn{3}{|c|}{ Frequência do uso de bebida alcoólica pelo namorado/marido/companheiro } \\
\hline Só nas festas/socialmente & 14 & 21,5 \\
\hline Uma vez por semana & 10 & 15,4 \\
\hline Duas vezes por semana & 5 & 7,7 \\
\hline De três vezes ou mais por semana & 5 & 7,7 \\
\hline Não bebe & 15 & 23,1 \\
\hline Não respondeu & 16 & 24,6 \\
\hline \multicolumn{3}{|c|}{ Drogas usadas em casa por algum familiar ou até mesmo a mulher } \\
\hline Comprimidos & 13 & 20,0 \\
\hline Injetáveis & 1 & 1,5 \\
\hline Crack & 1 & 1,5 \\
\hline Maconha & 3 & 4,6 \\
\hline Cocaína & 1 & 1,5 \\
\hline Ninguém na sua casa faz uso destas drogas & 43 & 66,2 \\
\hline
\end{tabular}


Não respondeu

Uso de drogas em casa por algum familiar ou até mesmo a mulher

A senhora

Namorado/marido/companheiro

Filho

Outro parente que mora na casa

Não respondeu

Total

Fonte: Dados da pesquisa, 2018.

\section{DISCUSSÃO}

Pesquisas revelam que a mulher possui maior vulnerabilidade frente a episódios de violência atribuindo a características predominantes, tais como idade jovem, baixa escolaridade, companheiro fixo e com condições econômicas precárias (BARROS et al., 2016).

Tal situação também foi evidenciada no estudo realizado no Rio de Janeiro entre os anos de 2003 e 2008 que a maioria das mulheres violentadas, as quais prestaram queixa na delegacia especializada apresentava apenas o ensino fundamental completo, além do mais, a maioria pertencia ao grupo em fase reprodutiva e economicamente ativa entre 20 a 39 anos de idade (MOURA; NETTO; SOUZA, 2012).

Os baixos salários apresentados no presente estudo são fatores desencadeantes de conflitos familiares, uma vez que, a fome, o lazer, a educação e a baixa qualidade de vida são condições que acarretam instabilidade dentro do lar entre os membros da família, criando um ambiente propício ao desenvolvimento de conflitos que podem culminar com a violência contra as mulheres em âmbito doméstico (ACOSTA; GOMES; BARLEM, 2013).

Um estudo desenvolvido no âmbito jurídico na cidade de Campina Grande, Paraíba, constatou nos registros arquivados na Delegacia da Mulher que os agressores possuíam perfil semelhante ao encontrado na presente pesquisa; em 
relação ao nível de escolaridade dos agressores, 55,8\% deles estudaram e 38,2\% correspondem à faixa etária de 22 a 32 anos (BRASILEIRO; MELO, 2016).

Quanto aos maus-tratos ou agressões presenciadas em casa quando pequena ou jovem a maioria das mulheres afirmaram que não conviviam com tal situação. Segundo Santos et al. (2010) o não reconhecimento das situações de violência doméstica associa-se a banalização da mesma no âmbito familiar, por não ser reconhecida como tal, agregada ao sentimento de medo, vergonha ou culpa à exposição de tal situação íntima são condições que podem produzir subrelato desse fenômeno.

Presenciar desentendimentos dos pais, discussões verbais e violência física já são por si só, algo entendido como traumático, pois essas situações são geralmente consideradas como momentos mais marcantes da vida de um jovem; desse modo compreende-se que o testemunho das situações de violência pode ser nocivo a saúde mental de um indivíduo quando o sofrimento da violência diretamente (LIMA; WERLANG, 2011).

Das mulheres participantes do estudo a maioria declarou não ter sido maltratada emocionalmente e nem fisicamente $(56,9 \%)$. Os dados acerca do histórico de violência sofrida ao longo da vida encontrados no presente estudo destoam de Morais (2009) apresentada na literatura da sua dissertação, em que o mesmo encontrou uma maioria correspondente a $51 \%$ de mulheres que sofreram violência ao longo da vida.

Contudo, vale destacar que a prevalência da violência doméstica apresentada no presente estudo produz um alerta, uma vez que em média $41 \%$ das mulheres relataram algum tipo de violência sofrida, o que não representa um indicador irrelevante, logo que tais dados deveriam ser menores, bem como podem estar subrelatados.

Em concordância, é importante destacar que quando se avalia a vivência da violência doméstica durante toda a vida da mulher, a prevalência torna-se ainda mais elevada, pois, uma mulher que esteve em situação de violência, tem mais chances de continuar a vivenciá-la em outro momento de sua vida (SILVA, 2006).

No que diz respeito à violência vivenciada nos últimos 12 meses através de ofensas com palavras, agressão física com empurrões, chutes e machucados a 
maioria revelou não ter vivenciado. É sabido que a violência está em torno de brigas, ofensas, empurrões, humilhações e vergonha e, apesar das marcas físicas serem uma constatação em fato da violência, elas permanecem existindo nas "pequenas" agressões recaindo efeitos negativos na saúde da mulher da mesma forma (SILVA et al, 2015).

Quando considerado os sítios mais frequentemente atingidos durante a vivência da violência física. Observa-se a homogeneidade proporcional entre os locais atingidos, os quais foram o braço $(6,2 \%)$, cabeça $(3,1 \%)$, membros superiores e inferiores (ombro, abdome, perna e braço) correspondendo a $3 \%$ e rosto $(1,5 \%)$. Silva e Oliveira (2016) apresentaram com seu estudo sobre as características epidemiológicas da violência contra a mulher no Distrito Federal, 2009 a 2012, em que os órgãos genitais $(15,7 \%)$ e a cabeça/face $(12,9 \%)$ são as regiões corporais mais atingidas no ato da violência contra a mulher, sendo o uso da força corporal e/ou espancamento para a realização de tal prática a mais utilizada.

Em relação a violência sexual, o sexo forçado ocorreu em 12,3\% das participantes; estudo de Barros et al. (2016), observa como fator fortemente associado à violência doméstica a manutenção de relações sexuais forçada, com chance aumentada em mais de cinco vezes para esse tipo de violência o ambiente doméstico, caracterizando-se o denominado estupro conjugal.

Cumpre aqui destacar que ainda existem mulheres que são forçadas a manter relações sexuais contra sua vontade, uma vez que os companheiros alegam sexo no convívio familiar como um direito básico, fato esse agravado devido algumas mulheres serem desprovidas de conhecimento e não compreender que o sexo forçado é um ato de violência (VIEIRA et al, 2014).

A utilização de álcool e drogas evidenciada no presente estudo demonstra uma questão de saúde pública, pois agregam problemas de ordem física, psíquica, familiar, social, econômica e laboral que afetam o convívio familiar e estão diretamente relacionados a situações de violência no geral, inclusive doméstica (VIEIRA ET AL., 2014).

Em se tratando da frequência do uso de bebida alcoólica pelo namorado/marido/companheiro, o álcool foi considerado a substância mais utilizada socialmente $(21,5 \%)$. Por outro lado, as vítimas estão mais propensas ao uso de 
cigarro e ao maior consumo de álcool e drogas, uma vez que o uso de bebida alcoólica pode estar associado à violência física, como apresentado no estudo de Leite et al. (2017) em que a maioria das mulheres relataram ser usuárias de drogas e consumir bebida alcoólica.

De acordo com Acosta et al. (2015) a interação de elementos que atuam sobre o comportamento afetivo diminui ou aumenta as chances de uma pessoa tornar-se vítima ou agressor, tal como o uso de drogas, que têm sido referido como capaz de precipitar diversas situações de violência.

Portanto, o risco da associação do álcool e outras drogas com a agressão doméstica contra a mulher não ocorre apenas com os usuários abusivos e regulares, mas também entre usuários moderados ou eventuais como afirma o estudo de Rabello e Caldas Júnior (2007).

\section{CONCLUSÕES}

Apesar da violência doméstica auto relatada entre mulheres atendidas no planejamento familiar não predominar entre as participantes, os dados se expressam de suma relevância para discussão tendo em vista que boa parte das participantes não respondeu a alguns questionamentos específicos sobre violência, o que incitar reflexões sobre o desconhecimento das mulheres sobre o que compreende situações de violência ou silenciamento do fenômeno por parte das mesmas.

Conclui-se que a prevalência de mulheres vítima de violência doméstica no cenário analisado representa um dado expressivo o que evidencia um alerta para o serviço de saúde abordado, bem como ressalta-se a importância de considerar os fatores socioeconômicos e comportamentais mais presentes entre vítimas e agressores como sinais de propensão a vulnerabilidade da mulher à violência.

Dessa forma espera-se que os dados do presente estudo, assim como as suas limitações possibilitem e fomentem novas pesquisas envolvendo a temática com recortes transversais e longitudinais, assim como inquietem profissionais da área a abordagem da temática em seus serviços de saúde afim de propiciar cada 
vez mais empoderamento da mulher em vista do rompimento do ciclo da violência doméstica.

\section{REFERÊNCIAS BIBLIOGRÁFICAS}

ACOSTA, D. F et al. Violência contra a mulher por parceiro íntimo: (in) visibilidade do problema. Texto \& Contexto Enfermagem, v.24, n.1, p. 121-7, 2015.

ACOSTA, D. F; GOMES, V. L. O; BARLEM, E. L. D. Perfil das ocorrências policiais de violência contra a mulher. Acta Paulista de Enfermagem, v.26, n.6, p.547-53, 2013.

BARROS, E. $\mathrm{N}$ et al. Prevalência e fatores associados à violência por parceiro íntimo em mulheres de uma comunidade em Recife/Pernambuco, Brasil. Ciência \& Saúde Coletiva, v.21, n.2, p.591-598, 2016.

BRASILEIRO, A. E; MELO, M. B. Agressores na violência doméstica: um estudo do perfil sóciojurídico. Revista de Gênero, Sexualidade e Direito, Curitiba, v. 2, n. 2, p. 189- 208, 2016.

FERREIRA, M. F et al. Efeito da violência física entre parceiros íntimos no índice de massa corporal em mulheres adultas de uma população de baixa renda. Caderno de Saúde Pública, Rio de Janeiro, v.31, n.1, p.1-13, jan., 2015.

FONSECA, D. H; RIBEIRO, C. G; LEAL, N. S. B. Violência doméstica contra a mulher: realidades e Representações sociais. Psicologia \& Sociedade, v.24, n.2, p.307-314, 2012.

LEITE, F. M. C et al. Violência contra a mulher em Vitória, Espírito Santo, Brasil. Revista de Saúde Pública, v.51, 33, 2017.

LIMA, G. Q; WERLANG, B. S. G. Mulheres que sofrem violência doméstica: contribuições da psicanálise. Psicologia em Estudo, Maringá, v. 16, n. 4, p. 511-520, 2011.

MIURA, Paula Orchiucci et al. VIOLÊNCIA DOMÉSTICA OU VIOLÊNCIA INTRAFAMILIAR: ANÁLISE DOS TERMOS. Psicol. Soc., v. 30, e179670, 2018.

MORAIS, A. C. Depressão em mulheres vítimas de violência doméstica. Dissertação apresentada ao Programa de Pós-Graduação da Escola de Enfermagem da Universidade Federal da Bahia, como requisito para obtenção de grau de Mestre em Enfermagem, Salvador, 2009. 126p.

MOURA, M. A. V; NETTO, L. A; SOUZA, M. H. N. Perfil sociodemográfico de mulheres em situação de violência assistidas nas delegacias especializadas. Escola Anna Nery, v.16, n.3, p.435-442, 2012.

RABELLO, P. M; CALDAS JÚNIOR, A. F. Violência contra a mulher, coesão familiar e drogas. Revista Saúde Pública, v.41, n.6, p. 970-8, 2007.

RIBEIRO, C. G; COUTINHO, M. L. L. Representações sociais de mulheres vítimas de violência doméstica na cidade de João Pessoa-PB. Psicologia e Saúde, v.3, n.1, p.52-59, 2011.

SANTOS, S. A et al. Violência doméstica durante a gestação: um estudo descritivo em uma unidade básica de saúde no Rio de Janeiro. Caderno de Saúde Coletiva, Rio de Janeiro, v.18, v.4, p.483-93, 2010. 
SILVA, C. D at al. Violência contra a mulher: agressores usuários de drogas ilícitas. Revista de Pesquisa Cuidado é Fundamental Online, Rio de Janeiro, v.7, n.2, p.2494-2504, abr./jun., 2015.

SILVA, L. E. L; OLIVEIRA, M. L. C. Características epidemiológicas da violência contra a mulher no Distrito Federal, 2009 a 2012. Epidemiologia em Serviços de Saúde, Brasília, v.25, n.2, p.331-342, abr./jun., 2016.

SILVA, L.; OLIVEIRA, M. Violência contra a mulher: revisão sistemática da produção científica nacional no período de 2009 a 2013. Ciência \& Saúde Coletiva, v. 20, n. 11, p. 3523-3532, 2015.

SILVA, M. A. Prevalência e fatores associados a violência doméstica contra as mulheres assistidas no Centro de Atenção à Mulher - CAM/IMIP, em Recife/Pernambuco. Dissertação (Mestrado). Curso de Mestrado em Saúde Materno Infantil do Instituto Materno Infantil Professor Fernando Figueira - IMIP. Recife, 2006. 105p.

VIEIRA, L. B et al. Abuso de álcool e drogas e violência contra as mulheres: denúncias de vividos. Revista Brasileia de Enfermagem, v.67, n.3, p.366-72, mai./jun., 2014. 